\title{
Diagnostic Cutoff Value for Ultrasonography in the Ulnar Neuropathy at the Elbow
}

\author{
Joo Hee Kim, MD, Sun Jae Won, MD, Won Ihl Rhee, MD, Hye Jung Park, MD, Hyeon Mi Hong, MD
}

Department of Rehabilitation Medicine, Yeouido St. Mary's Hospital,

The Catholic University of Korea College of Medicine, Seoul, Korea

Objective To determine the diagnostic cutoff values of ultrasonographic measurements in ulnar neuropathy at the elbow (UNE).

Methods Twenty-five elbows of 23 patients ( 9 females, 16 males) diagnosed with UNE and 30 elbows of 30 healthy controls (15 females, 15 males) were included in our study. The ulnar nerve cross-sectional area (CSA) was measured at the Guyon canal, midforearm, and maximal swelling point (MS) around the elbow (the cubital tunnel inlet in healthy controls). CSA measurements of the ulnar nerve at each point, the Guyon canal-to-MS ulnar nerve area ratio (MS/G), and the midforearm-to-MS ulnar nerve ratio (MS/F) were calculated.

Results Among the variables, only CSA at MS, MS/G, and MS/F displayed significant differences between the control and patient groups. The cutoff value for diagnosing UNE was $8.95 \mathrm{~mm}^{2}$ for the CSA at MS (sensitivity $93.8 \%$, specificity $88.3 \%$ ), 1.99 for the MS/G (sensitivity $75.0 \%$, specificity $73.3 \%$ ), and 1.48 for the MS/F (sensitivity 93.8\%, specificity $95.0 \%)$.

Conclusion These findings may be helpful to diagnose UNE.

Keywords Ulnar neuropathies, Ultrasonography, Cross-sectional area, Cut-off value

\section{INTRODUCTION}

Ulnar neuropathy at the elbow (UNE) is the second most common entrapment neuropathy after carpal tunnel syndrome [1]. The diagnosis of UNE is traditionally based on a patient's medical history, clinical examina-

Received July 3, 2014; Accepted September 22, 2014

Corresponding author: Hyeon Mi Hong

Department of Rehabilitation Medicine, Yeouido St. Mary's Hospital, The Catholic University of Korea College of Medicine, 10 63(yuksam)-ro, Yeongdeungpo-gu, Seoul 150-713, Korea

Tel: +82-2-3779-1383, Fax: +82-2-3779-1581, E-mail: idwom@hanmail.net

(c) This is an open-access article distributed under the terms of the Creative Commons Attribution Non-Commercial License (http://creativecommons. org/licenses/by-nc/3.0) which permits unrestricted noncommercial use distribution, and reproduction in any medium, provided the original work is properly cited.

Copyright (C) 2015 by Korean Academy of Rehabilitation Medicine tion, and electrodiagnostic study. However, the wide spectrum of clinical findings and many limitations of electrodiagnostic study often make the diagnosis of UNE difficult [2-4]. Many studies have shown that highresolution ultrasonography can be a valuable diagnostic modality for UNE [1,3-7], especially in entrapment neuropathies and for documenting nerve swelling proximal to sites of entrapment $[3,8]$. Previous studies have compared the cross-sectional area (CSA) of the nerve at the site of entrapment with that of controls, and demonstrated that there is a difference in the CSA of the nerve between the two groups [9-11]. The CSA is the most widely accepted measurement for diagnosing entrapment neuropathies $[3,5,6,8]$. Although there are many studies that have evaluated the CSA of the entrapped nerves, there is 
no definite consensus on the standard ultrasonographic measurement method and its diagnostic value in patients with UNE [4-7]. Some studies have suggested considering CSAs larger than $7.5-8.3 \mathrm{~mm}^{2}$ at the level of the epicondyle, as the threshold value for UNE $[1,7,12]$, while other researchers have suggested a cutoff point of $10 \mathrm{~mm}^{2}$ $[3,13]$. Therefore, due to variations in the reported normal range, further research is necessary for establishing a consensus. Also, in a few studies, the swelling ratio was measured by comparing the nerve size at the level of the elbow with the nerve size at another level $[7,14]$. However, the usefulness of this ratio has not been confirmed, and other, more useful sites of comparison have not been evaluated. Also, the sensitivity and specificity of the swelling ratio for diagnosing UNE have not been studied.

The purpose of this study was to determine the diagnostic cutoff values of the ultrasonographic measurements, and to document the diagnostic usefulness of the swelling ratio in ulnar neuropathy at the elbow.

\section{MATERIALS AND METHODS}

This study was approved by the Institutional Review Board of our institution. Thirty asymptomatic healthy volunteers who did not have any relevant diseases were recruited for the control group (15 females, 15 males) and 30 unilateral elbows were examined. A total of 25 elbows of 23 patients ( 9 females, 16 males), who visited our electrodiagnostic clinic from January 2012 to May 2013 and were diagnosed with UNE were included in the patient group. Patients with polyneuropathy, acute trauma, or a previous history of ulnar surgery were excluded.
Electrodiagnosis was based on the American Association of Electrodiagnostic Medicine criteria [15], which included the presence of one of the following abnormalities: slowing of the absolute nerve conduction velocity above the elbow, a decrease in the nerve conduction velocity of more than $10 \mathrm{~m} / \mathrm{s}$ across the elbow, a decrease in the amplitude of more than $20 \%$, absence of ulnar sensory responses, or denervation in the muscles innervated by the ulnar nerve on electromyography.

Ultrasonographic examinations were performed with VOLUSON e (GE Healthcare, Waukesha, WI, USA) with a 7-12 MHz linear array transducer. During evaluation, both the patients and controls were sitting with their elbows flexed at $90^{\circ}$ and their shoulders flexed at $60^{\circ}$. The forearm was fully supinated and supported by an arm rest. The examiner carefully placed the probe perpendicular to the nerve in order to minimize anisotropy. The probe was placed on the skin by applying minimum pressure and the CSA was measured. The ulnar nerve was traced from the distal to the proximal side of the arm, and the CSA was measured at several points by tracing just inside the hyperechoic rim of the nerve. Also, the examiner slightly changed the location of the probe until the smallest CSA of the nerve was obtained; where anisotropy became minimal. The CSA was measured three times at each site and the mean measurement was calculated and recorded. All ultrasonographic measurements were performed by the same operator, who had no information about the clinical and electrophysiological findings or the severity of the disease.

In the both groups, the ulnar nerve CSA was measured at the Guyon canal, midforearm (where the nerve sepa-
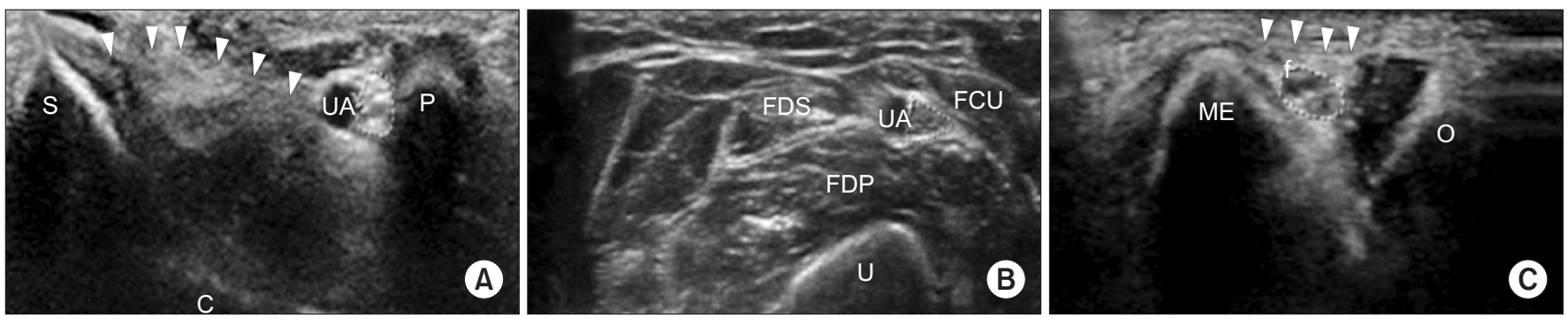

Fig. 1. Cross-sectional views of the ulnar nerve ultrasonographic tracing in normal control. The ulnar nerve is shown within the dotted line. (A) Wrist at the Guyon canal level. Arrowheads show the flexor retinaculum. (B) Midforearm, where the nerve splits from the ulnar artery. (C) Cubital tunnel inlet at the medial epicondyle. The Osborne ligament is partially visualized (arrowheads). C, capitate bone; FCU, flexor carpi ulnaris; FDP, flexor digitorum profundus; FDS, flexor digitorum superficialis; ME, medial epicondyle; O, olecranon; P, pisiform bone; S, scaphoid bone; U, ulnar bone; UA, ulnar artery. 
rates from the ulnar artery), and cubital tunnel inlet. Around the cubital tunnel inlet, the maximal swelling of the ulnar nerve was measured (Fig. 1). To obtain the swelling ratio by using the CSA, the following ratios were calculated: the CSA of the ulnar nerve at the Guyon canal to the largest CSA at the elbow (MS/G), and the CSA at the midforearm to the largest CSA at the elbow (MS/F). In controls, instead of largest CSA at the elbow, the ulnar nerve CSA at the cubital tunnel inlet was used to calculate the swelling ratio.

\section{Statistical analysis}

Statistical analyses were performed with SPSS ver. 17 for Windows (SPSS Inc., Chicago, IL, USA). The CSA measurements and their ratios between the patients and controls were compared by means of a Mann-Whitney U test. The distribution of non-paretic variables was examined using a Mann-Whitney U test and all tests were considered significant at $\mathrm{p}$-value equal or less than 0.05. A receiver operating characteristic (ROC) analysis was performed to assess the efficiency of the ultrasonographic measurements in diagnosing UNE.

\section{RESULTS}

Twenty-five elbows of 23 patients (9 females, 16 males) diagnosed with UNE and 30 elbows of 30 healthy controls (15 females, 15 males) were studied. The baseline characteristics were not significantly different between the two groups (Table 1).

In the electrodiagnostic study, ulnar nerve conduction abnormalities were seen in only six elbows. Both ulnar nerve conduction abnormalities and abnormal spontaneous activities in ulnar nerve innervated muscles were seen in 19 elbows. Most patients with UNE had some degree of nerve conduction velocity (NCV) slowing (defined as $<50 \mathrm{~m} / \mathrm{s}$ ) across the elbow, with a mean velocity $38.9 \pm 14.5 \mathrm{~m} / \mathrm{s}$. On the other hand, the mean NCV of the ulnar nerve below elbow to the wrist was $53.9 \pm 12.7 \mathrm{~m} / \mathrm{s}$. Because multiple short segment stimulation studies were not performed, the exact location of the neuropathy was not known. However, in all patients, a short segment across the elbow was used for the nerve conduction studies, so all neuropathies were within a segment of the ulnar nerve extending $4 \mathrm{~cm}$ distal and $6 \mathrm{~cm}$ proximal to the medial

Table 1. Baseline characteristics of subjects

\begin{tabular}{|lccc}
\hline \multicolumn{1}{c}{ Variable } & Control group $(\mathbf{n}=\mathbf{3 0})$ & Ulnar neuropathy group $(\mathbf{n}=\mathbf{2 5})$ & p-value \\
\hline Height $(\mathrm{cm})$ & $165.2 \pm 7.2$ & $164.5 \pm 5.4$ & 0.032 \\
\hline Weight $(\mathrm{kg})$ & $63.6 \pm 10.7$ & $66.0 \pm 10.7$ & 0.995 \\
BMI & $23.2 \pm 3.2$ & $24.3 \pm 3.1$ & 0.719 \\
\hline Sex (male:female) & $15: 15$ & $16: 9$ & - \\
Age (yr) & $45.2 \pm 13.5$ & $50.8 \pm 13.5$ & 0.592 \\
\hline Duration of symptoms (mo) & - & $34.7 \pm 32.0$ & - \\
\hline Side (right:left) & $30: 0$ & $11: 14$ & - \\
\hline
\end{tabular}

Values are presented as mean \pm standard deviation or the number of cases.

Table 2. Ultrasonographic measurements of ulnar nerve in controls and patients with ulnar neuropathy at the elbow

\begin{tabular}{lccc}
\hline & Control & Ulnar neuropathy & p-value \\
\hline CSA at Guyon canal $\left(\mathrm{mm}^{2}\right)$ & $4.4 \pm 0.6$ & $4.7 \pm 0.9$ & 0.174 \\
CSA at midforearm $\left(\mathrm{mm}^{2}\right)$ & $6.6 \pm 1.2$ & $6.0 \pm 1.5$ & 0.067 \\
CSA at MS or cubital tunnel inlet $\left(\mathrm{mm}^{2}\right)$ & $7.5 \pm 1.3$ & $12.2 \pm 4.9$ & $<0.001^{*}$ \\
MS/G & $1.7 \pm 0.3$ & $2.7 \pm 1.2$ & $<0.001^{*}$ \\
MS/F & $1.2 \pm 0.2$ & $2.2 \pm 1.1$ & $<0.001^{*}$ \\
\hline
\end{tabular}

Values are presented as mean \pm standard deviation.

CSA, cross-sectional area; MS, maximal swelling point; MS/G, Guyon canal-to-MS ulnar nerve area ratio; MS/F, midforearm-to-MS ulnar nerve ratio.

${ }^{*} \mathrm{p} \leq 0.05$, statistically significant. 
Table 3. Sensitivity and specificity of cutoff values for each ultrasonographic parameter for diagnosing ulnar neuropathy at the elbow

\begin{tabular}{lccc}
\hline & $\begin{array}{c}\text { Cutoff value } \\
\left(\mathbf{m m}^{2}\right)\end{array}$ & $\begin{array}{c}\text { Sensitivity } \\
(\mathbf{\%})\end{array}$ & $\begin{array}{c}\text { Specificity } \\
\mathbf{( \% )}\end{array}$ \\
\hline CSA at MS & 8.95 & 93.8 & 88.3 \\
MS/G & 1.99 & 75.0 & 73.3 \\
MS/F & 1.48 & 93.8 & 95.0 \\
\hline
\end{tabular}

CSA, cross-sectional area; MS, maximal swelling point; MS/G, Guyon canal-to-MS ulnar nerve area ratio; MS/F, midforearm-to-MS ulnar nerve ratio.

epicondyle.

The mean ulnar nerve CSA at the cubital tunnel inlet in the control groups was $7.5 \pm 1.3 \mathrm{~mm}^{2}$. The mean ulnar nerve CSA at the site of maximal swelling in patients with UNE was $12.2 \pm 4.9 \mathrm{~mm}^{2}$, and it showed a significant difference between the two groups. In contrast, the mean ulnar nerve CSA in Guyon canal and midforearm was not significantly different between the control and patients with UNE groups. The swelling ratios of the ulnar nerve CSA at the site of maximal swelling compared with the area of Guyon canal $(2.7 \pm 1.2)$ and with the area at the midforearm $(2.2 \pm 1.1)$ were significantly larger than the corresponding swelling ratios in the control group (Table 2).

An ROC analysis was performed to compare the diagnostic sensitivity and specificity of the ultrasonographic measurements and their ratios. The CSA at MS, MS/G, and MS/F had a larger area under the curve, and the cutoff value for diagnosing UNE was $8.95 \mathrm{~mm}^{2}$ for the CSA at MS (sensitivity $93.8 \%$, specificity $88.3 \%$ ), 1.99 for the MS/ G (sensitivity $75.0 \%$, specificity $73.3 \%$ ), and 1.48 for the MS/F (sensitivity 93.8\%, specificity 95.0\%) (Table 3, Fig. 2).

\section{DISCUSSION}

Ulnar neuropathy at the elbow is a common entrapment mononeuropathy and may result from trauma within the cubital tunnel during repetitive flexion [1]. The physiologic compression of the ulnar nerve within the cubital tunnel may occur because of a reduction in the volume of the tunnel whenever the elbow is flexed. Pressures within the cubital tunnel have been shown to increase 20 -fold with elbow flexion and simultaneous flexor carpi ulnaris muscle contraction [16]. Also, the Osborne's fascia, which is a relatively rigid structure, might be a source of com-

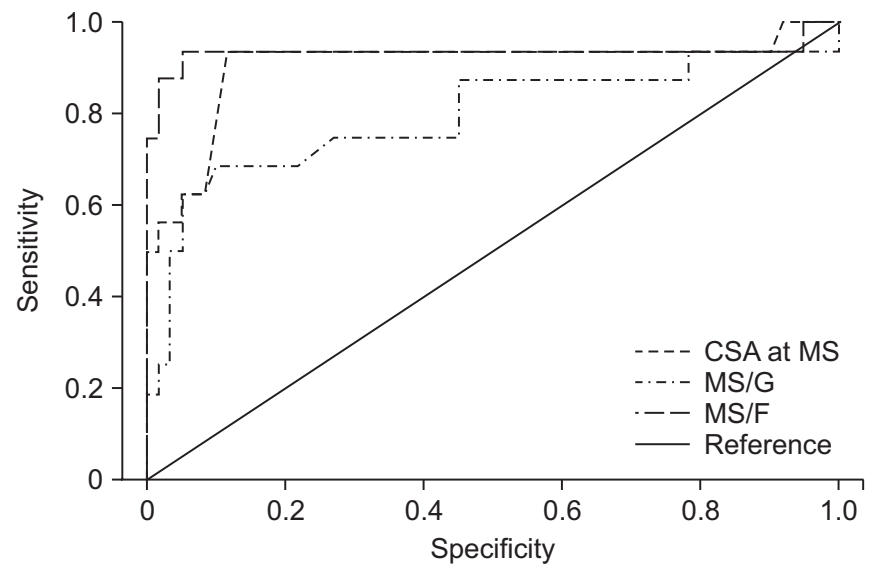

Fig. 2. A receiver operator characteristic (ROC) curve showing the relationship between the sensitivity and specificity for each ultrasonographic parameter in the diagnosis of ulnar neuropathy at the elbow. CSA, cross-sectional area; MS, maximal swelling point; MS/G, Guyon canal-to-MS ulnar nerve area ratio; MS/F, midforearmto-MS ulnar nerve ratio.

pression $[16,17]$.

The diagnosis of ulnar neuropathy at the elbow usually is made by electrodiagnostic study, which has shown sensitivities ranging from $37 \%$ to $86 \%$ and specificities of $95 \%$ or greater [15].

However, the many limitations of electrodiagnostic study often make the diagnosis of UNE difficult [2-4]. High-resolution ultrasonography can provide further information about the pathology and increase the sensitivity and specificity of electrodiagnostic testing to $78 \%-98 \%$ for the diagnosis of UNE $[4,18]$.

The main ultrasonographic finding in UNE is focal nerve enlargement just proximal to the compression site. The CSA measurement at the site of maximal swelling has been used to improve diagnostic reliability $[4,7,18]$. However, there are some inconsistencies in the literature as to which diagnostic cutoff value of CSA for ulnar neuropathy at the elbow should be considered abnormal [19]. While some investigators suggested considering CSA > $7.5-8.3 \mathrm{~mm}^{2}$ at the site of maximal swelling as the cutoff value $[1,7,12]$, others researchers suggested $10 \mathrm{~mm}^{2}$ as the cutoff value for diagnosing UNE $[3,13]$. In this study, ultrasonographic measurements of ulnar nerve CSA were compared between 30 elbows of healthy controls and 25 elbows of patients with UNE. There was no significant difference in the mean CSA of the ulnar nerve at the Guyon 
canal and midforearm area between the two groups. The CSA measurement at the maximal swelling point was significantly larger in the patient group $\left(12.2 \pm 4.9 \mathrm{~mm}^{2}\right)$ than in the control group $\left(7.5 \pm 1.3 \mathrm{~mm}^{2}\right)$, and its cutoff value was $8.95 \mathrm{~mm}^{2}$ (sensitivity $93.8 \%$, specificity $88.3 \%$ ), which is consistent with that found in prior studies considering the lower body mass index (BMI) of the subjects in our study compared with prior studies $[6,7]$.

To improve the accuracy of an ultrasonographic evaluation of UNE, in addition to the largest CSA, the nerve CSA ratio can be measured $[7,14]$. The effectiveness of the swelling ratio between the CSA at the site of maximal enlargement and CSA at an unaffected site was assessed in recent studies, and some authors have reported that the swelling ratio did not improve the accuracy than that was obtained by using only the CSA at a single site of swelling $[6,7,10]$. However, many demographic factors can affect the CSA measurement of the nerve, especially the patient's weight and BMI, and these factors have been reported to be significantly associated with the CSA of the nerve. Also, in cases where polyneuropathy may be present, the ratio may be a more important index than CSA for diagnosing UNE [7,20-23].

The swelling ratios of the ulnar nerve CSA at the site of maximal swelling compared to the area of the Guyon canal $(2.7 \pm 1.2)$ and with the area at the midforearm $(2.2 \pm 1.1)$ were statistically significantly different than the corresponding ratios in the controls. Moreover, the sensitivity analysis showed that if an upper limit ratio of 1.48:1 for MS/F was chosen as the cutoff point, it yielded a sensitivity of $93.8 \%$ and specificity of $95.0 \%$ in our data. Therefore, the CSA ratio of the nerve may be useful in diagnosing UNE, and it may improve the diagnostic accuracy in individuals who are very thin or morbidly obese and have a borderline nerve area.

There are some limitations to this study. First, this study enrolled a relatively small number of participants, and therefore it may difficult to generalize the results. Second, the feature of ulnar nerve subluxation or dislocation was not evaluated in this study. Third, UNE can be divided into cubital tunnel syndrome and retrocondylar compression syndrome [24]. However, in our study, these two groups were not separated. Fourth, because a nerve enlargement ratio between the area of the nerve at the elbow and the area of the nerve proximally was not measured, the difference of the swelling ratio between the mid-humerus and the maximal swelling point around the cubital tunnel inlet was not known. Therefore, further study may be necessary.

In conclusion, ultrasonography may be a helpful tool to complement electrodiagnostic studies for diagnosing UNE. High-resolution ultrasound can trace the ulnar nerve from the distal to the proximal arm, and measurements can be taken at several points defined by anatomic landmarks or clinically important points. Also, it can be used to easily visualize the ulnar nerve at the elbow. The main ultrasonographic finding in UNE is focal nerve enlargement just proximal to the compression site. The CSA at that point was measured by tracing just inside the hyperechoic rim of the nerve. The CSA measurement of the ulnar nerve at the site of maximal swelling at the elbow may be used to diagnose UNE, and the CSA ratio and MS/ F may also improve the diagnostic reliability.

\section{CONFLICT OF INTEREST}

No potential conflict of interest relevant to this article are reported.

\section{REFERENCES}

1. Chiou HJ, Chou YH, Cheng SP, Hsu CC, Chan RC, Tiu CM, et al. Cubital tunnel syndrome: diagnosis by high-resolution ultrasonography. J Ultrasound Med 1998;17:643-8.

2. Kitzinger HB, Aszmann OC, Moser VL, Frey M. Significance of electroneurographic parameters in the diagnosis of chronic neuropathy of the ulnar nerve at the elbow. Handchir Mikrochir Plast Chir 2005;37:276-81.

3. Wiesler ER, Chloros GD, Cartwright MS, Shin HW, Walker FO. Ultrasound in the diagnosis of ulnar neuropathy at the cubital tunnel. J Hand Surg Am 2006;31:1088-93.

4. Beekman R, Schoemaker MC, Van Der Plas JP, Van Den Berg LH, Franssen H, Wokke JH, et al. Diagnostic value of high-resolution sonography in ulnar neuropathy at the elbow. Neurology 2004;62:767-73.

5. Nakamichi K, Tachibana S. Ultrasonographic measurement of median nerve cross-sectional area in idiopathic carpal tunnel syndrome: diagnostic accuracy. Muscle Nerve 2002;26:798-803.

6. Yoon JS, Kim BJ, Kim SJ, Kim JM, Sim KH, Hong SJ, et 
al. Ultrasonographic measurements in cubital tunnel syndrome. Muscle Nerve 2007;36:853-5.

7. Bayrak AO, Bayrak IK, Turker H, Elmali M, Nural MS. Ultrasonography in patients with ulnar neuropathy at the elbow: comparison of cross-sectional area and swelling ratio with electrophysiological severity. Muscle Nerve 2010;41:661-6.

8. Yoon JS, Walker FO, Cartwright MS. Ultrasonographic swelling ratio in the diagnosis of ulnar neuropathy at the elbow. Muscle Nerve 2008;38:1231-5.

9. Mondelli M, Filippou G, Frediani B, Aretini A. Ultrasonography in ulnar neuropathy at the elbow: relationships to clinical and electrophysiological findings. Neurophysiol Clin 2008;38:217-26.

10. Gruber H, Glodny B, Peer S. The validity of ultrasonographic assessment in cubital tunnel syndrome: the value of a cubital-to-humeral nerve area ratio (CHR) combined with morphologic features. Ultrasound Med Biol 2010;36:376-82.

11. Ozturk E, Sonmez G, Colak A, Sildiroglu HO, Mutlu $\mathrm{H}$, Senol MG, et al. Sonographic appearances of the normal ulnar nerve in the cubital tunnel. J Clin Ultrasound 2008;36:325-9.

12. Hobson-Webb LD, Massey JM, Juel VC, Sanders DB. The ultrasonographic wrist-to-forearm median nerve area ratio in carpal tunnel syndrome. Clin Neurophysiol 2008;119:1353-7.

13. Jacob D, Creteur V, Courthaliac C, Bargoin R, Sassus B, Bacq C, et al. Sonoanatomy of the ulnar nerve in the cubital tunnel: a multicentre study by the GEL. Eur Radiol 2004;14:1770-3.

14. Volpe A, Rossato G, Bottanelli M, Marchetta A, Caramaschi P, Bambara LM, et al. Ultrasound evaluation of ulnar neuropathy at the elbow: correlation with electrophysiological studies. Rheumatology (Oxford) 2009;48:1098-101.
15. American Association of Electrodiagnostic Medicine; American Academy of Neurology; American Academy of Physical Medicine and Rehabilitation. Practice parameter for electrodiagnostic studies in ulnar neuropathy at the elbow: summary statement. Muscle Nerve 1999;22:408-11.

16. Contreras MG, Warner MA, Charboneau WJ, Cahill DR. Anatomy of the ulnar nerve at the elbow: potential relationship of acute ulnar neuropathy to gender differences. Clin Anat 1998;11:372-8.

17. Kara M, Ozcakar L, De Muynck M, Tok F, Vanderstraeten G. Musculoskeletal ultrasound for peripheral nerve lesions. Eur J Phys Rehabil Med 2012;48:665-74.

18. Polatsch DB, Melone CP Jr, Beldner S, Incorvaia A. Ulnar nerve anatomy. Hand Clin 2007;23:283-9.

19. Yalcin E, Unlu E, Akyuz M, Karaahmet OZ. Ultrasound diagnosis of ulnar neuropathy: comparison of symptomatic and asymptomatic nerve thickness. J Hand Surg Eur Vol 2014;39:167-71.

20. Won SJ, Kim BJ, Park KS, Yoon JS, Choi H. Reference values for nerve ultrasonography in the upper extremity. Muscle Nerve 2013;47:864-71.

21. Cartwright MS, Passmore LV, Yoon JS, Brown ME, Caress JB, Walker FO. Cross-sectional area reference values for nerve ultrasonography. Muscle Nerve 2008;37:566-71.

22. Cartwright MS, Shin HW, Passmore LV, Walker FO. Ultrasonographic findings of the normal ulnar nerve in adults. Arch Phys Med Rehabil 2007;88:394-6.

23. Landau ME, Barner KC, Campbell WW. Effect of body mass index on ulnar nerve conduction velocity, ulnar neuropathy at the elbow, and carpal tunnel syndrome. Muscle Nerve 2005;32:360-3.

24. Park GY, Kim JM, Lee SM. The ultrasonographic and electrodiagnostic findings of ulnar neuropathy at the elbow. Arch Phys Med Rehabil 2004;85:1000-5. 